\title{
Incidence and trends of ophthalmic cancer in Singapore: Data from Singapore Cancer Registry
}

\author{
Chin Sheng Teoh, ${ }^{1}$ MMed (Ophth), Preethi Jeyabal, ${ }^{1}$ MRCS (Edin), Stephanie M Young, ${ }^{1}$ FAMS, Vivien SY Lim, ${ }^{1}$ MMed (Ophth)
}

\begin{abstract}
Introduction: Limited data are available on the incidence of primary ophthalmic cancers worldwide. We describe the incidence and trends of primary ophthalmic cancers in Singapore.

Methods: Data on ophthalmic cancers diagnosed in Singapore from 1996 to 2016 were retrieved from the Singapore Cancer Registry for analysis. All were histologically proven primary ophthalmic cancers. Calculations of incidence and age-specific frequency of ophthalmic malignancy were made.

Results: A total of 297 cases were included, with males constituting 59.9\%. The race distribution was $78.5 \%$ Chinese, $16.5 \%$ Malay, 3.7\% Indians and 1.3\% others. There was an overall increase in ophthalmic malignancies. The mean age of onset was 47.4 years. The most common cancers were retinoblastoma $(93.3 \%)$ in patients younger than 15 years, and lymphoma $(71.3 \%)$ in patients aged 15 years and older. There has been an increase in lymphomas from $16.7 \%$ in 1968-1995 to $71.3 \%$ in 1996-2016 in those aged 15 years and older. The most common types of ophthalmic cancer according to location are lymphoma of the orbit, conjunctiva, cornea and lacrimal gland; retinoblastoma of the retina; and malignant melanoma of the choroid and ciliary body.

Conclusion: Our study reported the incidence and trends of ophthalmic cancer in the Singapore population and showed an overall increase in ophthalmic malignancies in Singapore from 1996-2016. A substantial increase in lymphomas over the last 2 decades was noted. The data could aid clinicians, epidemiologists and policymakers in implementing strategies to address trends in ophthalmic cancers and spur aetiological research to improve quality of life in patients with such cancers.
\end{abstract}

Ann Acad Med Singap 2021;50:297-305

Keywords: Aetiology; epidemiology; malignancy; orbital cancers

\section{INTRODUCTION}

Ophthalmic cancers are commonly encountered in clinical practice and are an important cause of morbidity and mortality. ${ }^{1,2}$ Globally, the incidence of ophthalmic cancers have been increasing in the past 2 to 3 decades. ${ }^{3-6}$ Data on recent incidence of primary ophthalmic cancers, comprising intraocular and extraocular cancers, have not been well reported in Singapore. Apart from a single epidemiological report on intraocular, conjunctival and orbital cancers in Singapore from 1968 to $1995,{ }^{1}$ there has been no detailed or recent epidemiological description of ophthalmic cancers in Singapore since.
The purpose of our study was to describe the epidemiological characteristics and histological patterns of 297 cases of primary intraocular, conjunctival and orbital cancers diagnosed in Singapore from 1996 to 2016 and to address the change in patterns of the various ophthalmic malignancies over the years. Similar to the previous study, eyelid tumours were excluded for analysis as epidemiology of eyelid tumours in Singapore was reported by 2 groups of authors over the separate study periods of 1968-1995 and 1996-2008., ${ }^{2,7}$

With rapidly increasing advances in tumour biology, therapy and instrumentation, being aware of the latest trends and changes will be of paramount importance not

\footnotetext{
${ }^{1}$ Department of Ophthalmology, National University Hospital, Singapore

Correspondence: Dr Vivien Lim Sin Yi, Department of Ophthalmology, National University Hospital, 5 Lower Kent Ridge Road, Medical Centre, Level 17, Singapore 119074.

Email: vivien_sy_lim@nuhs.edu.sg
} 


\section{CLINICAL IMPACT}

\section{What is New}

- The incidence and trends of ophthalmic cancer in Singapore showed an overall increase in number from 1996 to 2016.

- Lymphoma overtook melanoma as the most common ophthalmic cancer in adult population with significant rise in the number over the last 2 decades

\section{Clinical Implications}

- The data of this study aid clinicians, epidemiologists and policymakers in implementing strategies to address trends in ophthalmic cancers and spur further aetiological research to improve quality of life in patients with such cancers.

only to clinicians but also to the epidemiologists and policymakers to implement changes accordingly and to stimulate further aetiological research involving these malignancies., ${ }^{2,8}$

\section{METHODS}

After obtaining approval from the institution's ethical board Domain Specific Review Board (study reference number: 2017/01223), we performed a retrospective non-interventional study on all patients with ophthalmic cancers in Singapore from 1996 to 2016 using data from the Singapore Cancer Registry. In Singapore, a comprehensive cancer registration is ensured through notifications received from medical practitioners, pathology laboratories, haematology laboratories and departments, and healthcare institutions. ${ }^{9}$ All notifications were corroborated by clinical medical records to ensure accuracy of information. The registry data covered all ophthalmic cancers diagnosed in Singapore, including both Singapore residents and non-residents. The registered items included each patient's unique identification number, sex, age, date of diagnosis, location of tumours and histological data. Duplication was eliminated according to the national registration identification number (NRIC) unique to each resident in Singapore, ${ }^{9}$ or passport number, which is unique to each foreign patient. For this study, we included primary ophthalmic cancers that were diagnosed based on histopathological examination and coded according to the 10th revision of the International Statistical Classification of Diseases and Related Health Problems (ICD), site codes 69.0 to $69.9 .{ }^{10}$
Code 69 includes malignancies of the conjunctiva (code 69.0), cornea (code 69.1), retina (code 69.2), choroid (code 69.3), ciliary body(code 69.4), lacrimal gland and duct (code 69.5), orbit (code 69.6), overlapping lesion of eye and adnexa (code 69.8), and unspecified parts of the eye (code 69.9). ${ }^{10}$ Calculations of incidence and age-specific frequency of ophthalmic malignancy were made. The incidence was derived by dividing the number of cases by the total population and then multiplying by $1,000,000$. The population denominators used in the calculation were based on data published by the Singapore Department of Statistics. ${ }^{11}$

\section{RESULTS}

A total of 350 cases were retrieved, $53(15.1 \%)$ of which did not have a site specified (code 69.9) or origin determined and were omitted from the analysis. Hence, 297 cases were included in our study. Table 1 shows the demographics of the patients. The majority $(59.9 \%)$ were male and more than three-quarters $(78.5 \%)$ were Chinese.

There was an overall increase in ophthalmic malignancies in Singapore residents from 1996 to 2016. Fig. 1 shows the trends in ophthalmic malignancy incidence and Fig. 2 shows the age-specific frequencies of ophthalmic malignancies. The mean age of onset was 47.4 years.

The breakdown of histological diagnoses of various ophthalmic malignancies in patients younger than 15 years, and 15 years and older are summarised in Table 1. Overall, the majority of the histological diagnoses were lymphoma (56.9\%), retinoblastoma (18.9\%), malignant melanoma (10.8\%) and squamous cell carcinoma $(3.4 \%)$. The most common histology seen was retinoblastoma (93.3\%) in those younger than 15 years and lymphoma $(71.3 \%)$ in those aged 15 years and above. Table 2 presents the frequency of the various ophthalmic subsites and the histopathological diagnoses within each subsite. The orbit was the most common site of involvement, followed by retina, conjunctiva and cornea, lacrimal gland, and uveal tract.

\section{DISCUSSION}

Malignant ophthalmic tumours are rare but potentially vision- and life-threatening. ${ }^{8}$ In this study, we reported the incidence and trends of ophthalmic cancer in our Singapore population, showing an overall increase in the incidence of ophthalmic malignancies in Singapore from 1996 to 2016. Retinoblastoma was the most common ophthalmic malignancy in the paediatric age group, 


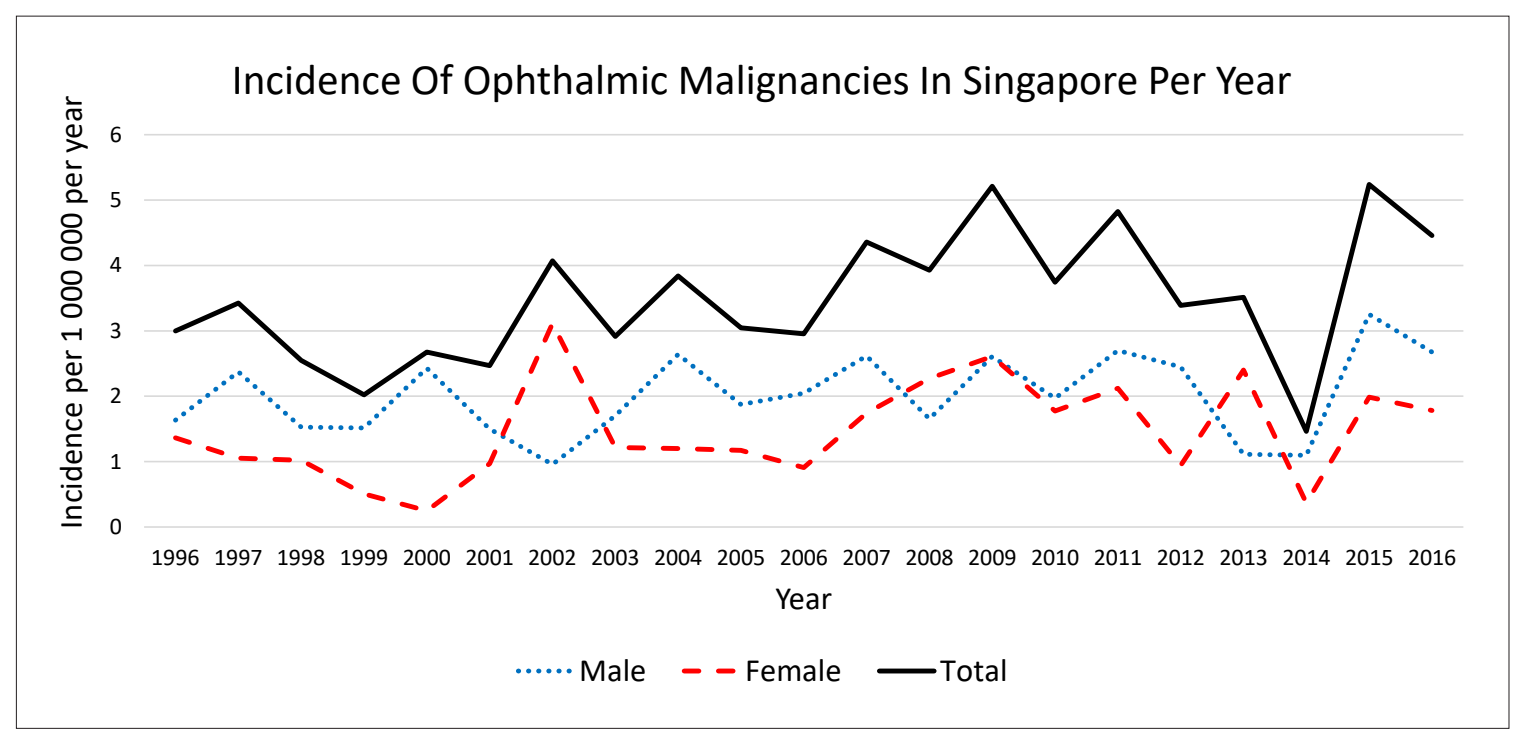

Fig. 1. Incidence of ophthalmic malignancies in Singapore per year from 1996 to 2016.

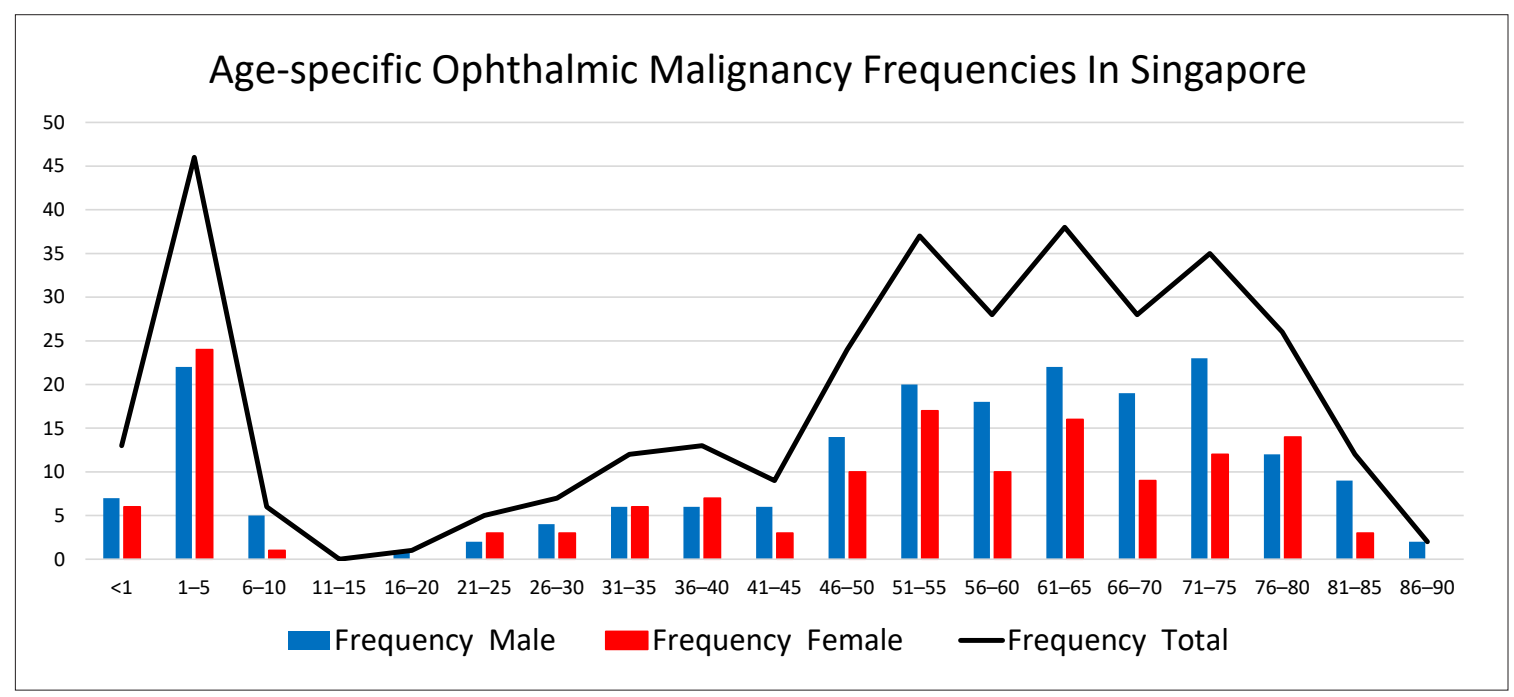

Fig. 2. Age-specific ophthalmic malignancy frequencies in Singapore from 1996 to 2016.

while the number of lymphoma cases was the highest in the adult population and overall population. The orbit was the most common site of malignancy in the eye.

The data of all cases in our study were 100\% histologically proven. These compare favourably with data from analyses of cancer registries of other countries, with their corresponding percentage of histologically proven cases: Birmingham, UK $(92.0 \%)$, Victoria, Australia (83.0\%) and Hong Kong (61.0\%) for ocular cancers with ICD code 190 during 1983-1987; South Korea cancer registry for ocular melanoma with ICD codes C69.0-C69.9 from 1999 to 2011 (79.1\%); and report based on the Taiwan cancer registry on ophthalmic cancers from 1979 to $1996(80.0 \%))^{1,3,4}$
The $100 \%$ rate of histologically verified cases in our study reflects a high level of sensitivity and accuracy of the dataset. In addition, cancers diagnosed in all clinics and hospitals in Singapore were registered using the patients' NRIC or passport number, thus eliminating duplication. The Singapore National Registry of Diseases (Cancer Notification) Regulations 2009 also ensures a comprehensive coverage of reportable diseases through the mandatory reporting and collection of information from healthcare providers. ${ }^{9}$

To date, there has only been 1 study looking at the epidemiology of ophthalmic cancers in Singapore from 1968 to 1995 . Our study serves as a follow-up to that study and provides details of the epidemiology of 
Table 1. Characteristics and histology of 297 ophthalmic malignancies in Singapore from 1996 to 2016

\begin{tabular}{|c|c|c|c|c|c|c|c|c|c|}
\hline \multirow[t]{2}{*}{ Histology } & \multicolumn{2}{|c|}{ Case } & \multirow{2}{*}{$\begin{array}{c}\text { Sex } \\
\text { Male:Female }\end{array}$} & \multicolumn{2}{|c|}{ Age (years) } & \multicolumn{4}{|c|}{ Race } \\
\hline & $\mathbf{n}$ & $\%$ & & Mean & Range & Chinese & Malay & Indian & Other \\
\hline \multicolumn{10}{|l|}{ Patients aged $<15$ years } \\
\hline Retinoblastoma & 56 & 93.3 & $29: 27$ & 2.3 & $0.1-6.7$ & 41 & 6 & 7 & 2 \\
\hline Rhabdomyosarcoma & 4 & 6.7 & 4:0 & 7.3 & $4.5-10.0$ & 3 & 1 & 0 & 0 \\
\hline Total & 60 & 100 & 33:27 & & & 44 & 7 & 7 & 2 \\
\hline \multicolumn{10}{|l|}{ Patients aged $\geq 15$ years } \\
\hline Lymphoma & 169 & 71.3 & 110:59 & 60.6 & $25.0-86.0$ & 130 & 35 & 3 & 1 \\
\hline Malignant melanoma & 32 & 13.5 & $15: 17$ & 54.9 & $20.0-82.0$ & 27 & 3 & 1 & 1 \\
\hline Squamous cell carcinoma & 14 & 5.9 & $9: 5$ & 77.8 & $72.0-83.5$ & 13 & 1 & 0 & 0 \\
\hline Sarcoma & 4 & 1.7 & $3: 1$ & 59.0 & $33.0-75.0$ & 3 & 1 & 0 & 0 \\
\hline Adenocarcinoma & 4 & 1.7 & $3: 1$ & 56.0 & $54.0-58.0$ & 3 & 1 & 0 & 0 \\
\hline Other & 4 & 1.7 & $3: 1$ & 69.0 & $57.0-81.0$ & 3 & 1 & 0 & 0 \\
\hline Total & 237 & 100 & 145:92 & & & 189 & 42 & 4 & 2 \\
\hline Total cases $(\%)$ & 297 & & $\begin{array}{c}178: 119 \\
(59.9: 40.1)\end{array}$ & & & $\begin{array}{c}233 \\
(78.5)\end{array}$ & $\begin{array}{c}49 \\
(16.5)\end{array}$ & $\begin{array}{c}11 \\
(3.7)\end{array}$ & $\begin{array}{c}4 \\
(1.3)\end{array}$ \\
\hline
\end{tabular}

ophthalmic cancers from 1996 to 2016 and of changes in trends over the years. ${ }^{1}$ Compared with the previous study, our study also shows bimodal distribution of cases with a peak around 1-5 years and another peak later at about 50-80 years, as illustrated in Fig. 2.

Table 3 compares the various histological subtypes in our current study and the 1968-1995 study from Singapore. In the 1968-1995 study, retinoblastoma $(53.6 \%)$ was the most common cancer type, followed by malignant melanoma $(19.2 \%)$ and squamous cell carcinoma $(11.2 \%)$. In comparison, our study shows that lymphoma $(56.9 \%)$ was the most common ophthalmic cancer, followed by retinoblastoma (18.9\%) and malignant melanoma (10.8\%). A comparison of the cancer types in the $<15$ and $\geq 15$ years age groups in the 2 time periods is presented in Table 3. A notable exponential increase in lymphoma cases from 1968-1995 to $1996-2016$ is seen in the $\geq 15$ years age group. Table 4 lists the 3 most common cancers in studies from Singapore, Taiwan and New York, along with the corresponding time periods, in comparison with those in our present study.

In our study, lymphoma was found to be the most common type of tumour. On analysing the various subsites, lymphoma was the most common type of tumour in the orbit, conjunctiva, cornea and lacrimal system, and the second most common type in the retina, choroid and ciliary body. This result correlates with a recent international multicentre retrospective cohort study of ocular adnexal marginal zone B-cell lymphoma, which found the orbit $(66.0 \%)$ and the conjunctiva $(37.0 \%)$ to be the most frequently involved anatomical structures. ${ }^{13}$ The incidence of general nonHodgkin's lymphoma has substantially increased in the Western population since the $1980 \mathrm{~s} .{ }^{14-17}$

In our study, the frequency of ocular lymphoma was noted to have exponentially increased from $16.7 \%$ (1968-1995) to $67.4 \%(1996-2016)$ in those aged 15 years and older. ${ }^{1}$ There have been reports of increase in incidence of generalised non-Hodgkin's lymphoma among Singapore residents, but ours is the first study to report an increase in incidence of ocular lymphoma in Singapore over the last few decades. ${ }^{6}$ This finding is in consensus with studies from other parts of the world and with worldwide data supporting rapid increase in ocular lymphoma incidence in the last few decades. ${ }^{18-20}$ Two studies from the US are standing examples of the substantial increase in its incidence since 1980s. ${ }^{21,22}$

Conjunctival and corneal tumours encompass a broad range of diagnoses. The most important malignant 
Table 2. Subsites and histopathological subtypes of ophthalmic malignancy cases in Singapore from 1996 to 2016

\begin{tabular}{|c|c|c|}
\hline Subsite & Histology type & n (\%) \\
\hline \multicolumn{2}{|l|}{ Orbit } & $114(38.4)$ \\
\hline \multirow[t]{9}{*}{1} & Lymphoma & $100(87.7)$ \\
\hline & Marginal zone B-cell lymphoma & 69 \\
\hline & Small B-cell lymphoma & 12 \\
\hline & Large B-cell lymphoma & 11 \\
\hline & Follicular lymphoma (grade 1, $\mathrm{n}=1$; & 4 \\
\hline & grade $3, n=3$ ) & 2 \\
\hline & Malignant lymphoma & 1 \\
\hline & Lymphoplasmacytic lymphoma & 1 \\
\hline & Mantle cell lymphoma & \\
\hline \multirow[t]{3}{*}{2} & Rhabdomyosarcoma & $4(3.5)$ \\
\hline & Alveolar rhabdomyosarcoma & 2 \\
\hline & Subtype not specified & 2 \\
\hline 3 & Sarcoma & $3(2.6)$ \\
\hline 4 & Adenocarcinoma & $2(1.8)$ \\
\hline \multirow[t]{3}{*}{5} & Malignant melanoma & $2(1.8)$ \\
\hline & Mixed type & 1 \\
\hline & Epithelioid cell & 1 \\
\hline 6 & Squamous cell carcinoma & $2(1.8)$ \\
\hline 7 & Adenoid cystic carcinoma & $1(0.8)$ \\
\hline \multicolumn{2}{|c|}{ Conjunctiva and cornea } & $55(18.5)$ \\
\hline \multirow[t]{10}{*}{1} & Lymphoma & $36(65.5)$ \\
\hline & Conjunctiva & \\
\hline & - Marginal zone B-cell lymphoma & 26 \\
\hline & - Small B-cell lymphoma & 3 \\
\hline & - Follicular lymphoma & 3 \\
\hline & - Mantle cell lymphoma & 1 \\
\hline & Cornea & \\
\hline & - Bowen disease & 1 \\
\hline & - Burkitt lymphoma & 1 \\
\hline & - Follicular lymphoma & 1 \\
\hline \multirow[t]{3}{*}{2} & Squamous cell carcinoma & $10(18.2)$ \\
\hline & Conjunctiva & 8 \\
\hline & $\begin{array}{l}\text { Conjunctiva and cornea involvement } \\
\text { (overlapping) }\end{array}$ & 2 \\
\hline \multirow[t]{4}{*}{3} & Malignant melanoma & $8(14.5)$ \\
\hline & Conjunctiva & \\
\hline & - Mixed type & 8 \\
\hline & Cornea & $0(0)$ \\
\hline \multirow[t]{3}{*}{4} & Papillary squamous cell carcinoma & $1(1.8)$ \\
\hline & Conjunctiva & 1 \\
\hline & Cornea & $0(0)$ \\
\hline
\end{tabular}

Table 2. Subsites and histopathological subtypes of ophthalmic malignancy cases in Singapore from 1996 to 2016 (Cont'd)

\begin{tabular}{|c|c|c|}
\hline Subsite & Histology type & n (\%) \\
\hline \multicolumn{2}{|l|}{ Retina } & $57(19.2)$ \\
\hline 1 & Retinoblastoma & $56(98.2)$ \\
\hline \multirow[t]{2}{*}{2} & Lymphoma & $1(1.8)$ \\
\hline & Large B-cell lymphoma & 1 \\
\hline \multicolumn{2}{|c|}{ Lacrimal } & $44(14.8)$ \\
\hline \multirow[t]{6}{*}{1} & Lymphoma & $27(61.4)$ \\
\hline & Marginal zone B-cell lymphoma & 20 \\
\hline & Large B-cell lymphoma & 4 \\
\hline & Malignant lymphoma & 1 \\
\hline & Mantle cell lymphoma & 1 \\
\hline & Follicular lymphoma & 1 \\
\hline 2 & Adenoid cystic carcinoma & $9(20.4)$ \\
\hline 3 & Adenocarcinoma & $2(4.5)$ \\
\hline 4 & Lymphoepithelial carcinoma & $2(4.5)$ \\
\hline 5 & Basaloid carcinoma & $1(2.3)$ \\
\hline 6 & Malignant melanoma & $1(2.3)$ \\
\hline 7 & Malignant spindle cell & $1(2.3)$ \\
\hline 8 & Solitary fibrous tumour & $1(2.3)$ \\
\hline \multicolumn{2}{|c|}{ Choroid and ciliary body } & $27(9.1)$ \\
\hline \multirow[t]{7}{*}{1} & Malignant melanoma & $21(77.8)$ \\
\hline & Choroidal & 10 \\
\hline & - Mixed type & 5 \\
\hline & - Spindle A and B cell & 1 \\
\hline & & \\
\hline & Ciliary body & 5 \\
\hline & - Mixed type & 3 \\
\hline \multirow[t]{3}{*}{2} & Ciliary body lymphoma & $5(18.5)$ \\
\hline & Large B-cell lymphoma & 4 \\
\hline & Marginal zone B-cell lymphoma & 1 \\
\hline 3 & Ciliary body squamous cell carcinoma & $1(3.7)$ \\
\hline \multicolumn{2}{|l|}{ Total } & 297 (100) \\
\hline
\end{tabular}

tumours include ocular surface squamous neoplasia $(14.0 \%)$, melanoma $(12.0 \%)$ and lymphoma $(7.0 \%){ }^{23}$ In our study, the most common malignant ocular surface tumour was lymphoma, followed by squamous cell carcinoma and melanoma, with cases of the latter being much lower than those of the former two. This lower number is not surprising as melanoma is known to be a rare malignancy in the Asian population compared with 
Table 3. Comparison of the frequency of various histological subtypes during the periods of 1996-2016 and 1968-1995 in Singapore

\begin{tabular}{|c|c|c|c|c|}
\hline \multirow[t]{2}{*}{ Histology } & \multicolumn{2}{|c|}{$1968-1995$ study $^{1}$} & \multicolumn{2}{|c|}{ 1996-2016 study } \\
\hline & $\mathbf{n}$ & $\%$ & $\mathbf{n}$ & $\%$ \\
\hline \multicolumn{5}{|l|}{ Patients aged $<15$ years } \\
\hline Retinoblastoma & 66 & 95.7 & 56 & 93.3 \\
\hline Rhabdomyosarcoma & 2 & 2.9 & 4 & 6.7 \\
\hline Other & 1 & 1.4 & 0 & 0 \\
\hline Total & 69 & 100 & 60 & 100 \\
\hline \multicolumn{5}{|l|}{ Patients aged $>15$ years } \\
\hline Lymphoma & 9 & 16.7 & 169 & 71.3 \\
\hline Malignant melanoma & 23 & 42.6 & 32 & 13.5 \\
\hline Squamous cell carcinoma & 14 & 25.9 & 14 & 5.9 \\
\hline Adenoid cystic carcinoma & 2 & 3.7 & 10 & 4.2 \\
\hline Liposarcoma & 1 & 1.85 & 1 & 0.4 \\
\hline Sarcoma & 0 & 0 & 3 & 1.3 \\
\hline Adenocarcinoma & 1 & 1.85 & 4 & 1.7 \\
\hline Carcinoma, NOS & 1 & 1.85 & \multicolumn{2}{|c|}{ Excluded in our study } \\
\hline Others & 3 & 5.56 & 4 & 1.7 \\
\hline Total & 54 & 100 & 237 & 100 \\
\hline
\end{tabular}

NOS: not otherwise specified

Superscript number: Refer to REFERENCES

Table 4. Comparison of the 3 most common cancers in studies from Singapore, Taiwan and New York with those in our present study

\begin{tabular}{llll}
\hline City or country (study period) & Most common cancer & Second most common cancer & Third most common cancer \\
\hline Singapore (1968-1995) & Retinoblastoma (53.6\%) & Melanoma (19.2\%) & Squamous cell carcinoma (11.2\%) \\
Taiwan & Retinoblastoma (35.3\%) & Melanoma (17.9\%) & Lymphoma (13.8\%) \\
$(1979-1996)^{4}$ & & & \\
New York & Melanoma (70.4\%) & Retinoblastoma (9.8\%) & Squamous cell carcinoma (9.2\%) \\
$(1975-1986)^{12}$ & & & \\
Singapore (1996-2016) & Lymphoma (56.9\%) & Retinoblastoma (18.9\%) & Melanoma (10.8\%) \\
\hline
\end{tabular}

Superscript numbers: Refer to REFERENCES

Caucasians, with the annual incidence of around 0.15 cases per million people among Asians. ${ }^{23}$ Even so, melanoma is often associated with increased morbidity and mortality in people of darker skin and hence should not be overlooked. ${ }^{24}$ Immunodeficiency, exposure to ultraviolet (UV) radiation and human papillomavirus infections are postulated as risk factors for ocular surface squamous neoplasia. ${ }^{8}$ Overall, we noticed that the incidence of these tumours has decreased recently and their relation to these risk factors in our population have not yet been reported.

Lacrimal gland tumours are rare and constitute a wide spectrum of different entities ranging from benign epithelial and lymphoid lesions to high-grade carcinomas, lymphomas and sarcomas. Such tumours have large differences in prognosis and clinical management. They 
represent almost $10.0 \%$ of the space-occupying orbital lesions, with epithelial lesions accounting for $20.0-50.0 \%$ of the total. ${ }^{25}$ Among the epithelial lesions, 55.0\% are benign and $45.0 \%$ are malignant. ${ }^{26} \mathrm{As}$ reported in various studies, the most common malignant tumour of the lacrimal gland is adenoid cystic carcinoma, with a rare incidence of lymphoma. ${ }^{26-28}$ In a 1998 study from Texas, US, it was reported that out of all malignant tumours of the lacrimal gland, 24 cases $(85.7 \%)$ were epithelial tumours, with adenoid cystic carcinoma being most common (42.9\%) and lymphoma found in 4 cases $(14.3 \%){ }^{27}$ In contrast, our study found a surprisingly high percentage of all lacrimal gland tumours to be lymphomas $(61.4 \%)$. This figure is similar to the finding of a recent Korean study on biopsied chronic lacrimal gland masses, which showed that lymphoma was more common than other malignant epithelial tumours of the lacrimal gland. ${ }^{28}$ The study also found that the proportion of lymphoproliferative disease was higher than that of Western studies reported by Shields et al. ${ }^{25}$ and Font et al., ${ }^{27}$ while the proportion of epithelial tumours of the lacrimal gland was substantially lower than those reported in the Western studies.

Ciliary body lymphoma was found in 5 patients in our study. Intraocular lymphoma primarily originating from the ciliary body is exceedingly rare. To our knowledge, there have only been 6 other studies in the literature reporting 8 cases of primary ciliary body lymphoma worldwide. These include case reports published in 2004 describing a case of $360^{\circ}$ iris-ciliary body B-cell lymphoma masquerading as post-cataract uveitis, ${ }^{29}$ a 2012 study reporting 3 cases of primary iris-ciliary body B-cell lymphoma, ${ }^{30}$ a 2014 study reporting a $360^{\circ}$ ring-like choroidal lymphoma, ${ }^{31} 2$ case reports in 2018 describing primary ciliary body lymphoma extending into the anterior chamber, and a primary uveal lymphoma involving the choroid, ciliary body, iris and conjunctiva. ${ }^{32,33} \mathrm{~A}$ more recent case report documented a primary diffuse large B-cell lymphoma of the ciliary body. ${ }^{32}$

A 2006 study looking at the epidemiology of ocular lymphoma from 1992 to 2001 also reported that the incidence of ocular non-Hodgkin's lymphoma was highest among Asians and Pacific Islanders, lower in whites, and even lower in blacks. ${ }^{22}$ Similar to other studies, the majority of lymphomas were non-Hodgkin's B-cell type, with marginal B-cell lymphomas being the most common. ${ }^{34}$ The increase in the incidence of ocular lymphoma is a reflection of worldwide trend in the overall incidence of non-Hodgkin's lymphoma, which has increased approximately $80.0 \%$ since the $1970 \mathrm{~s} .{ }^{35}$
Although the increase in its incidence is probably related to the increase in incidence of immunocompromised states such as acquired immunodeficiency syndrome, increase in life expectancy, genetic susceptibility, diet and improvement in diagnostic tools, further studies are warranted to identify risk factors and mechanisms of increased incidence, especially among Asians, including the potential role of Chlamydia psittaci, Helicobacter pylori infections and association with Epstein-Barr virus. ${ }^{17,22,35}$

Choroidal melanomas are the most common primary intraocular malignancy in adults, accounting for $5.0 \%$ of all melanomas. ${ }^{8}$ This finding is in consensus with our study with 21 cases (16 choroidal melanomas and 5 ciliary body melanomas) contributing to $77.8 \%$ of all choroidal and ciliary body tumours. The most common subtype is mixed type, which is also similar to reports from other parts of the world. ${ }^{36,37}$ The increased incidence of melanoma among whites is in relation to their light pigmentation, which is a risk factor for melanoma. However, as most of Singapore's population (Chinese, Malay and Indians) have relatively more pigmentation than whites in general, the incidence of melanoma is relatively lower. The incidence of melanoma has decreased from $42.6 \%$ to $13.5 \%$ in the $\geq 15$ years age group when comparison is made with the 1968-1995 study. ${ }^{1}$ This decreased incidence is in contrast with the increasing incidence of melanoma reported in South Korea, Italy and France., ${ }^{3,38}$ However, looking at cancer registries and studies from most countries with white populations, the incidence of melanoma has more or less remained the same over the last few decades. ${ }^{39-41}$

Globally, cutaneous melanoma rates have increased in the last few decades with the increase in exposure to UV radiation. However, uveal melanoma rates in Singapore have not shown a similar trend. Although it is conceivable to expect an increase in incidence of melanoma with increased sun exposure especially in tropical countries like Singapore, the reverse is observed. Recent evidence suggests that UV exposure in the ocular region is different from that to the rest of the body. Various factors contribute to the lower exposure in the ocular region than to the rest of the body, and these factors include protective effects of the geometry of the face, presence of the eyebrows and superior orbital ridge as sunshade, back reflection from the eye and sunglasses, protection provided by structures like the eyelids and cataract from intraocular UV penetration, and the iris providing protection to the ciliary body posterior to it. ${ }^{42,43}$ 
The most common location of squamous cell carcinoma reported in our study is the conjunctiva, which is similar to findings of the 1968-1985 Singapore study and studies from other parts of the world. ${ }^{44-46}$ Eyelid cancers such as basal cell carcinoma, squamous cell carcinoma or sebaceous gland carcinoma were excluded in our series as these cases were listed as eyelid tumours and categorised under skin cancers.

\section{CONCLUSION}

Our study reported a change in ophthalmic malignancy trends in the Southeast Asian population in Singapore through the years. There was an overall increase in ophthalmic malignancies in Singapore. While retinoblastoma remained the most common ophthalmic malignancy in the paediatric age group, lymphoma overtook melanoma as the most common ophthalmic malignancy in the adult population with a significant rise over the years. Further studies examining possible causes for the trends observed may help us better understand and manage ophthalmic malignancies as a whole.

\section{Acknowledgement}

We thank the Singapore Cancer Registry of the National Registry of Diseases Office for providing the de-identified data for this study.

\section{REFERENCES}

1. Lee $\mathrm{SB}, \mathrm{Au}$ Eong $\mathrm{KG}$, Saw $\mathrm{SM}$, et al. Eye cancer incidence in Singapore. Br J Ophthalmol 2000;84:767-70.

2. Lim VS, Amrith S. Declining incidence of eyelid cancers in Singapore over 13 years: Population-based data from 1996 to 2008. Br J Ophthalmol 2012;96(12):1462-5.

3. Park SJ, Oh CM, Kim BW, et al. Nationwide incidence of ocular melanoma in South Korea by using the national cancer registry database (1999-2011). Invest Ophthalmol Vis Sci 2015; 56:4719-24.

4. Cheng CY, Hsu WM. Incidence of eye cancer in Taiwan: An 18-year review. Eye (Lond) 2004;18:152-8.

5. Larsen CL, Samuelson TW. Managing coexistent cataract and glaucoma with iStent. Surv Ophthalmol 2017;62:706-11.

6. Seow A, Lee J, Sng I, et al. Non-Hodgkin's lymphoma in an Asian population: 1968-1992 time trends and ethnic differences in Singapore. Cancer 1996;77:1899-904.

7. Lee SB, Saw SM, Au Eong KG, et al. Incidence of eyelid cancers in Singapore from 1968 to 1995. Br J Ophthalmol 1999;83:595-7.

8. Maheshwari A, Finger PT. Cancers of the eye. Cancer Metastasis Rev 2018;37:677-90.

9. National Registry of Diseases Office. Singapore Cancer Registry 50th Anniversary Monograph (1968-2017), November 2019. Available at: https://www.nrdo.gov.sg/publications/cancer. Accessed on 22 April 2021.

10. World Health Organization. The 10th revision of the International Statistical Classification of Diseases and Related Health Problems
(ICD-10). Available at: https://icd.who.int/browse10/2010/en\#/ C69-C72. Accessed on 22 April 2021.

11. Department of Statistics Singapore. Population and population structure. Available at: https://www.singstat.gov.sg/find-data/searchby-theme/population/population-and-population-structure/latest-data. Accessed on 20 March 2020.

12. Mahoney MC, Burnett WS, Majerovics A, et al. The epidemiology of ophthalmic malignancies in New York State. Ophthalmology 1990;97:1143-7.

13. Hindso TG, Esmaeli B, Holm F, et al. International multicentre retrospective cohort study of ocular adnexal marginal zone B-cell lymphoma. Br J Ophthalmol 2020;104:357-62.

14. Clarke CA, Glaser SL. Changing incidence of non-Hodgkin lymphomas in the United States. Cancer 2002;94:2015-23.

15. Groves FD, Linet MS, Travis LB, et al. Cancer surveillance series: Non-Hodgkin's lymphoma incidence by histologic subtype in the United States from 1978 through 1995. J Natl Cancer Inst 2000;92:1240-51

16. Howe HL, Wingo PA, Thun MJ, et al. Annual report to the nation on the status of cancer (1973 through 1998), featuring cancers with recent increasing trends. J Natl Cancer Inst 2001;93:824-42.

17. Sjo LD. Ophthalmic lymphoma: Epidemiology and pathogenesis. Acta Ophthalmol 2009;87(Thesis 1):1-20.

18. Mulay K, Narula R, Honavar SG. Primary vitreoretinal lymphoma. Indian J Ophthalmol 2015;63:180-6

19. Zhou $\mathrm{M}, \mathrm{Xu}$ G. Recent progress in the diagnosis and treatment of primary vitreoretinal lymphoma. Taiwan J Ophthalmol 2016;6:170-6.

20. Mochizuki M, Singh AD. Epidemiology and clinical features of intraocular lymphoma. Ocul Immunol Inflamm 2009;17:69-72.

21. Margo CE, Mulla ZD. Malignant tumors of the orbit. Analysis of the Florida Cancer Registry. Ophthalmology 1998;105:185-90.

22. Moslehi R, Devesa SS, Schairer C, et al. Rapidly increasing incidence of ocular non-Hodgkin lymphoma. J Natl Cancer Inst 2006;98:936-9.

23. Hu DN, Yu G, McCormick SA, et al. Population-based incidence of conjunctival melanoma in various races and ethnic groups and comparison with other melanomas. Am J Ophthalmol 2008; 145:418-23.

24. Shields CL, Markowitz JS, Belinsky I, et al. Conjunctival melanoma: Outcomes based on tumor origin in 382 consecutive cases. Ophthalmology 2011;118:389-95.e1-2.

25. Shields CL, Shields JA, Eagle RC, et al. Clinicopathologic review of 142 cases of lacrimal gland lesions. Ophthalmology 1989;96:431-5.

26. Wright JE, Stewart WB, Krohel GB. Clinical presentation and management of lacrimal gland tumours. Br J Ophthalmol 1979;63:600-6

27. Font RL, Smith SL, Bryan RG. Malignant epithelial tumors of the lacrimal gland: A clinicopathologic study of 21 cases. Arch Ophthalmol 1998;116:613-6.

28. Ahn C, Kang S, Sa HS. Clinicopathologic features of biopsied lacrimal gland masses in 95 Korean patients. Graefes Arch Clin Exp Ophthalmol 2019;257:1527-33.

29. Ahmed M, Androudi S, Brazitikos P, et al. 360 degrees iris-ciliary body B-cell lymphoma masquerading as post-cataract uveitis. Semin Ophthalmol 2004;19:127-9.

30. Mashayekhi A, Shields CL, Shields JA. Iris involvement by lymphoma: A review of 13 cases. Clin Exp Ophthalmol 2013; 41:19-26. 
31. Konstantinidis L, Angi M, Coupland SE, et al. Primary B-cell lymphoma of the ciliary body with $360^{\circ}$ ('ring'-like) growth pattern. Eye (Lond) 2014;28:355-6.

32. Kiratli H, Agin A, Buyukeren B, et al. Primary diffuse large B-cell lymphoma of the ciliary body. Ocul Immunol Inflamm 2019;27:407-9.

33. Wu RX, Yang T, Xu ZP. Primary uveal lymphoma effectively treated with radiotherapy: a case report and literature review. Nan Fang Yi Ke Da Xue Xue Bao 2018;38:371-74.

34. Shields CL, Shields JA, Carvalho C, et al. Conjunctival lymphoid tumors: Clinical analysis of 117 cases and relationship to systemic lymphoma. Ophthalmology 2001;108:979-84.

35. Chiu BC, Weisenburger DD. An update of the epidemiology of non-Hodgkin's lymphoma. Clin Lymphoma 2003;4:161-8.

36. Kaliki S, Shields CL. Uveal melanoma: Relatively rare but deadly cancer. Eye (Lond) 2017;31:241-57.

37. Singh AD, Shields CL, Shields JA. Prognostic factors in uveal melanoma. Melanoma Res 2001;11:255-63.

38. Stang A, Parkin DM, Ferlay J, et al. International uveal melanoma incidence trends in view of a decreasing proportion of morphological verification. Int J Cancer 2005;114:114-23.
39. Jovanovic P, Mihajlovic M, Djordjevic-Jocic J, et al. Ocular melanoma: An overview of the current status. Int J Clin Exp Pathol 2013;6:1230-44.

40. Singh AD, Topham A. Incidence of uveal melanoma in the United States: 1973-1997. Ophthalmology 2003;110:956-61.

41. Keenan TD, Yeates D, Goldacre MJ. Uveal melanoma in England: Trends over time and geographical variation. Br J Ophthalmol 2012;96:1415-9.

42. Behar-Cohen F, Baillet G, de Ayguavives T, et al. Ultraviolet damage to the eye revisited: Eye-sun protection factor (E-SPF®), a new ultraviolet protection label for eyewear. Clin Ophthalmol 2014;8:87-104.

43. Weis E, Vrouwe SQ, LeBaron DB, et al. Changes in ultraviolet radiation exposure to the ocular region: A population-based study. Cancers (Basel) 2019;11:719.

44. Malik MO, El Sheikh EH. Tumors of the eye and adnexa in the Sudan. Cancer 1979;44:293-303.

45. Ayiomamitis A. Epidemiologic features of cancer of the eye, orbit and related adnexa in Canada. Can J Ophthalmol 1989;24:269-74.

46. Sunderraj P. Malignant tumours of the eye and adnexa. Indian J Ophthalmol 1991;39:6-8. 